\title{
Analytical Procedure Quantitation Limit
}

National Cancer Institute

\section{Source}

National Cancer Institute. Analytical Procedure Quantitation Limit. NCI Thesaurus. Code C134248.

The lowest amount of analyte in a sample which can be quantitatively determined with suitable precision and accuracy. 